Tohoku J. Exp. Med., 2013, 229, 287-299

\title{
Perspective
}

\section{The Great East-Japan Earthquake and Devastating Tsunami: An Update and Lessons from the Past Great Earthquakes in Japan since 1923}

\author{
Akemi Ishigaki, ${ }^{1}$ Hikari Higashi, ${ }^{1}$ Takako Sakamoto ${ }^{1,2}$ and Shigeki Shibahara ${ }^{1,2}$ \\ ${ }^{1}$ The Tohoku Journal of Experimental Medicine, Tohoku University Medical Press, Sendai, Miyagi, Japan \\ ${ }^{2}$ Department of Molecular Biology and Applied Physiology, Tohoku University School of Medicine, Sendai, \\ Miyagi, Japan
}

\begin{abstract}
Japan has a long history of fighting against great earthquakes that cause structural damage/collapses, fires and/or tsunami. On March 11, 2011 at 14:46 (Friday), the Great East-Japan Earthquake (magnitude 9.0) attacked the Tohoku region (northeastern Japan), which includes Sendai City. The earthquake generated a devastating tsunami, leading to unprecedented disasters ( 18,500 victims) in coastal areas of Iwate, Miyagi and Fukushima prefectures, despite the fact that people living in the Tohoku region are well trained for tsunami-evacuation procedures, with the mindset of "Tsunami, ten-den-ko." This code means that each person should evacuate individually upon an earthquake. Sharing this rule, children and parents can escape separately from schools, houses or workplaces, without worrying about each other. The concept of ten-den-ko (individual evacuation) is helpful for people living in coastal areas of earthquake-prone zones around the world. It is also important to construct safe evacuation centers, because the March $11^{\text {th }}$ tsunami killed people who had evacuated to evacuation sites. We summarize the current conditions of people living in the disaster-stricken areas, including the consequences of the Fukushima nuclear accident. We also describe the disaster responses as the publisher of the Tohoku Journal of Experimental Medicine (TJEM), located in Sendai, with online support from Tokyo. In 1923, the Great Kanto Earthquake (magnitude 7.9) evoked a massive fire that destroyed large areas of Tokyo ( 105,000 victims), including the print company for TJEM, but the Wistar Institute printed three TJEM issues in 1923 in Philadelphia. Mutual aid relationships should be established between distant cities to survive future disasters.
\end{abstract}

Keywords: disaster; earthquake; evacuation; nuclear power plant; tsunami.

Tohoku J. Exp. Med., 2013 April, 229 (4), 287-299. C 2013 Tohoku University Medical Press

\section{Introduction}

Japan has a long history of fighting against earthquakes that are accompanied by structural damage/collapses, fires and/or tsunami. Two years have passed since the Great East-Japan Earthquake and Tsunami that occurred on March 11, 2011. However, many people living in coastal areas of the Tohoku region are still being forced to live inconvenient lives, with profound sadness due to the loss of families, friends, jobs, houses, and/or communities (Shibahara 2011). In addition, that earthquake and tsunami seriously damaged the Fukushima Dai-Ichi Nuclear Power Plant, causing longstanding global concerns (Schiermeier 2011; Garnier-Laplace et al. 2011; Buesseler et al. 2011). According to the Reconstruction Agency, about 315,000 people are still living in evacuation sites (as of February 15, 2013). As witnesses of these complex disasters, we update the damage and current conditions of the Tohoku region, which was most severely affected by the Great East-Japan Earthquake and devastating tsunami (Shibahara 2011). We also describe the disaster responses as the publisher of the Tohoku Journal of Experimental Medicine (TJEM), located in Sendai, the disaster-stricken area. The objectives of the TJEM are to publish original research papers that make novel and important contributions to the understanding of Medicine and Physiology and to provide the information worldwide from Japan. Experiencing the 2011 Great EastJapan Earthquake, we have updated the Editorial policy of the TJEM (Shibahara 2011); namely, the TJEM also deals with the fields of disaster prevention science, such as earth-

Received March 18, 2013; revised and accepted March 27, 2013. Published online April 13, 2013; doi: 10.1620/tjem.229.287. Akemi Ishigaki, Hikari Higashi, and Takako Sakamoto are editorial assistants of the Tohoku Journal of Experimental Medicine. Shigeki Shibahara is Editor-in-Chief, the Tohoku Journal of Experimental Medicine.

Correspondence: Shigeki Shibahara, M.D., Ph.D., Department of Molecular Biology and Applied Physiology, Tohoku University School of Medicine, Sendai, Miyagi 980-8575, Japan.

e-mail: shibahar@med.tohoku.ac.jp 
quake/tsunami research and earthquake archeology. The long-term goal of this new policy is to prevent/reduce human damage from natural disasters.

Since its foundation in 1920, the TJEM has experienced the three great earthquakes in Japan: the Great Kanto Earthquake in 1923, the Great Hanshin-Awaji Earthquake in 1995, and the Great East-Japan Earthquake in 2011 (Table 1). A great earthquake is defined as an earthquake that causes a large-scale disaster. The Great Kanto Earthquake (magnitude 7.9) caused a massive fire that killed most of the victims in the Kanto area, including Tokyo, Yokohama, and Chiba (105,000 deaths and missing persons) (Fig. 1), while the Great East-Japan Earthquake (magnitude 9.0) triggered a devastating tsunami in coastal areas of the Tohoku region (about 18,500 victims). In contrast, the 1995 Great Hanshin-Awaji Earthquake resulted in the collapse of many houses and buildings in the Hanshin area, including Nishinomiya, Ashiya, and Kobe Cities; thus, most of those victims were due to a crushing death or crush syndrome (Furukawa and Arai 2011). In addition, after the recovery of electricity, fires occurred at multiple sites, resulting in burn deaths. Thus, the types of injuries observed in the Great Hanshin-Awaji Earthquake are entirely different from those in the Great East-Japan Earthquake (Table 1). The Great Hanshin-Awaji Earthquake did not directly damage the Tohoku region, simply because of the long distance (about $650 \mathrm{~km}$ separate Kobe from Sendai). As a matter of course, relief teams the Tohoku region visited the Kanto area in 1923 and the Hanshin area in 1995, while many relief teams from Tokyo and Kobe helped us in the 2011 Great East-Japan Earthquake. Here, we update the consequences of the Great East-Japan Earthquake by focusing on the three prefectures of the Tohoku region that were severely damaged.
The Great East-Japan Earthquake and unprecedented tsunami disaster

On a cold Friday afternoon, March 11, 2011 at 14:46, a massive magnitude-9.0 earthquake attacked large areas of northeastern Japan, the Tohoku region, including Sendai City. The shaking of our building, the Tohoku University School of Medicine, continued for more than $3 \mathrm{~min}$ (Shibahara 2011). It was a strong and long-lasting earthquake that we had never previously experienced. We were unable to remain standing on the seventh floor, the condition of which was later graded as Seismic Intensity Lower 6. The earthquake caused a full-scale blackout and stopped gas and/or water supplies. Despite being the greatest earthquake ever recorded in Japan, there were a limited number of human deaths that were directly caused by the collapse of buildings or houses. Definitely, the quake-resistant and quake-absorbing buildings in the Tohoku region saved a large number of human lives, as evident from the number of injured persons (Table 1). On the other hand, the huge earthquake generated catastrophic tsunami, leading to unprecedented disasters in the Sanriku Coast and the seacoast areas of Miyagi and Fukushima (Shibahara 2011) (Table 2). According to the National Police Agency, the numbers of dead and missing persons were 15,882 and 2,668, respectively (as of March 11, 2013). Almost all of victims died by the tsunami, "All or Nothing" disaster (Shibahara 2012), as evident from the numbers of dead and injured persons (Table 1). The enormous power of tsunami is apparent from the scenes of coastal regions (Figs. 2, 3 and 4).

The Sanriku Coast consists of the entire coastal area of Iwate prefecture and the northeast coast of Miyagi prefecture (see Fig. 1). The Sanriku Coast is characterized by its ria structure that enhances the power of tsunami and has been frequently invaded by tsunami; namely, the Meiji Sanriku Tsunami in 1896 killed about 20,000 people and

Table 1. Comparison of the three Great Earthquakes in Japan since the foundation of the TJEM in 1920.

\begin{tabular}{|c|c|c|c|}
\hline & $\begin{array}{c}\text { Great Kanto } \\
\text { Earthquake and Fire }\end{array}$ & Great Hanshin-Awaji Earthquake & $\begin{array}{l}\text { Great East-Japan } \\
\text { Earthquake and Tsunami }\end{array}$ \\
\hline Date of onset & September 1, 1923 & January 17,1995 & March 11, 2011 \\
\hline Origin time (JST) & $11: 58: 32$ & $05: 46: 52$ & $14: 46: 23$ \\
\hline Magnitude & 7.9 & 7.3 & 9.0 \\
\hline Epicenter & $\begin{array}{c}35.1^{\circ} \mathrm{N} 139.5^{\circ} \mathrm{E} \\
(80 \mathrm{~km} \text { off the Sagami Bay) }\end{array}$ & $\begin{array}{l}34.4^{\circ} \mathrm{N} 135.2^{\circ} \mathrm{E} \\
\text { (Awaji Island ) }\end{array}$ & $\begin{array}{c}38.3^{\circ} \mathrm{N} 142.4^{\circ} \mathrm{E} \\
(130 \mathrm{~km} \text { off the Sanriku Coast) }\end{array}$ \\
\hline Feature of disaster & Fire, firestorm & Collapse of houses & Tsunami \\
\hline Dead or missing persons & about 105,000 & 6,437 & $18,550^{*}$ \\
\hline Injured persons & Unknown & 43,792 & $6,142 *$ \\
\hline Main cause of death & Burn & Crushing death & Drowning \\
\hline
\end{tabular}

JST indicates Japan standard time.

Data concerning the Great Kanto Earthquake and the Great Hanshin-Awaji Earthquake are provided by the Japan Meteorological Agency (http://www.seisvol.kishou.go.jp/eq/higai/higai-1995.html and the Cabinet Office, Government of Japan, respectively. Data of the Great East-Japan Earthquake are available from the Japan Meteorological Agency (http://www.seisvol.kishou.go.jp/eq/2011_03_11_ tohoku/index.html).

*Data shown are taken from the report of March 11, 2013 by the National Police Agency. 




Fig. 1. Distribution of the epicenters of the three Great Earthquakes.

Red crosses schematically show the epicenters of the three Great Earthquakes. Cities along the seacoast of East Japan are shown and the degrees of damage in those cities are shown in Table 2. The Tohoku region is highlighted, with neighboring prefectural capitals. The Sanriku Coast is shown in blue.

Table 2. The Pacific coast areas of East Japan attacked by the Great East-Japan Earthquake.

\begin{tabular}{|c|c|c|c|c|c|}
\hline Prefecture & Intensity (City) & Height of Tsunami & Dead* & Missing* & Injured* \\
\hline Aomori & Upper 5 (Hachinohe) & $>4.2 \mathrm{~m}$ (Hachinohe) & 3 & 1 & 111 \\
\hline Iwate & Lower 6 (Ofunato) & $>8.0 \mathrm{~m}$ (Ofunato) & 4,673 & 1,151 & 213 \\
\hline Miyagi & Upper 6 (Ishinomaki) & $>8.6 \mathrm{~m}$ (Ishinomaki) & 9,536 & 1,302 & 4,144 \\
\hline Fukushima & Lower 6 (Iwaki) & $>9.3 \mathrm{~m}$ (Soma) & 1,606 & 211 & 182 \\
\hline Ibaraki & Upper 6 (Hitachi) & $4.0 \mathrm{~m}$ (Oarai) & 24 & 1 & 711 \\
\hline Chiba & Upper 5 (Choshi) & $2.5 \mathrm{~m}$ (Choshi) & 21 & 2 & 256 \\
\hline Tokyo & Upper 5 (Chiyoda-ku) & $1.5 \mathrm{~m}$ (Harumi) & 7 & 0 & 117 \\
\hline Kanagawa & Upper 5 (Yokohama) & $1.55 \mathrm{~m}$ (Yokohama) & 4 & 0 & 137 \\
\hline Others & - & - & 8 & 0 & 271 \\
\hline Total & - & - & 15,882 & 2,668 & 6,142 \\
\hline
\end{tabular}

The intensity indicates the seismic intensity of the earthquake recorded at the indicated cities. The data of the Great East-Japan Earthquake are available from the Japan Meteorological Agency (http://www.seisvol.kishou.go.jp/eq/2011_03_11_tohoku/index.html).

*Data shown are taken from the report of March 11, 2013 by the National Police Agency. 


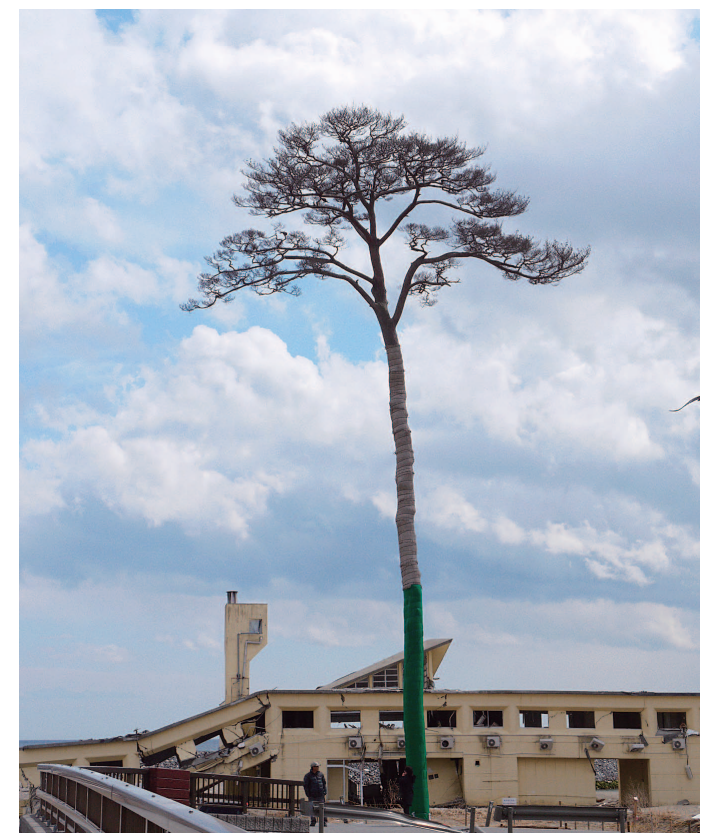

Fig. 2. "Tree of Hope" of Takata-matsubara, Rikuzentakata. Out of $\sim 70,000$ pine trees, only one tree was left standing in Takata-matsubara after the March $11^{\text {th }}$ tsunami. The photo was taken on March 25, 2012, when the pine tree was still alive (Courtesy of Ichiyo Shibahara).

the Showa Sanriku Tsunami in 1933 killed about 3,000 people (Satake et al. 2008). Thus, people living along the Sanriku Coast have been well trained for tsunami-evacuation procedures, with the strategy of "Tsunami, ten-den-ko," meaning that each person should evacuate immediately and separately to a safe place or a nearby hill, when a strong earthquake occurs (Yamashita 2008; Sekine 2011; Yamori 2013). "Ten-den-ko" is a dialect used in the Sanriku Coast area, with its long history of tsunami attacks. It is important for every family to build a mutual trust concerning their evacuation behavior in advance. Sharing the mindset of individual evacuation, "Tsunami, ten-den-ko", children and parents are able to escape separately from schools, houses or workplaces, without worrying about each other. In addition, many cities and towns along the Sanriku Coast have constructed high seawalls or made disaster-prevention forests by planting many pine trees to protect against tsunami. However, the 2011 tsunami, which was much greater than expected, destroyed those barriers (Fig. 2) and wiped out people who had evacuated to official shelters or seemingly safe buildings (Fig. 4).

When the 2011 Earthquake occurred, people knew that they had to evacuate from the seacoast area, according to the rule of individual evacuation, "Tsunami, ten-den-ko." Sadly however, some people went back to their houses to pick up family members or friends but most of them never returned. In Rikuzentakata, Iwate (see insert of Fig. 1), the tsunami killed many people (1,556 victims, Table 3 ), including the family of Ms. Sakiko Sugawara-Kamata. She had worked as an editorial assistant of TJEM for 7 years (2002-2008) and had greatly contributed to the development of the TJEM online. She, together with a lovely daughter, Azu (3 years) and a baby boy, Osuke ( 2 months), had just moved from Sendai to Rikuzentakata two weeks before the Earthquake because of her husband's business. The tsunami also killed her husband, Yoshimasa, because he immediately went home to pick up Sakiko and the children after the Earthquake. Circumstantial evidence suggests that Sakiko held the baby and Yoshimasa held the daughter in order to protect them against the killer tsunami. This sad story indicates that the rule of "Tsunami, ten-den-ko" is not necessarily easy to follow. We extend our heartfelt condolence to the victims and their families of the Great EastJapan Earthquake and devastating tsunami on March 11, 2011.

In Rikuzentakata, with the highest number of fatalities in Iwate (Table 3), there was a famous disaster-prevention forest that consists of about 70,000 pine trees along the beautiful beach, known as Takata-matsubara. The March $11^{\text {th }}$ tsunami wiped out the forest, except for one pine tree that appears a monument for the tsunami victims (Fig. 2). The survival of this pine tree had encouraged people to move on the recovery; thus, they named it "Tree of Hope" or "Miracle Pine." Eventually, however, the tree died due to salt damage. The city of Rikuzentakata has decided to preserve the specially processed pine tree as a symbol of restoration.

The tsunami attacked the Sendai plain after a 1,000-year interval

The March $11^{\text {th }}$ tsunami most severely damaged the coastal areas of the Sendai plain in Miyagi (Fig. 5), with the highest number of fatalities among the affected prefectures (Table 2). In Minami-Sanriku town (Minami stands for south), the municipal building for disaster-prevention measures is located at a position $400 \mathrm{~m}$ away from the Pacific Ocean. The tsunami killed about 30 public service workers who had evacuated to the roof of that three-story municipal building for disaster-prevention measures (Fig. 4A). Those officers working at the building did their best to encourage people to escape from the coming tsunami by using a Disaster prevention radio. There are a number of such sad stories about the loss of public service workers, officers, fire corps volunteers, and social workers in the tsunami-stricken areas. The relevant information (in Japanese) is available at the website (MEMORY EVER-DAISHINSAI: http://memory.ever.jp/tsunami/higeki_bosai-tyosya.html). In addition, the Public Shizugawa Hospital (126 beds) is located near the Minami-Sanriku municipal building and consists of a fourstory building and a five-story building. The tsunami passed through the fourth floor of the Public Shizugawa Hospital (Fig. 4B), causing the deaths of 70 patients and 4 staff members, but did not reach the fifth floor of the five-story building, to which many of the patients and hospital staff members had evacuated. It should be noted that the hospital staff 


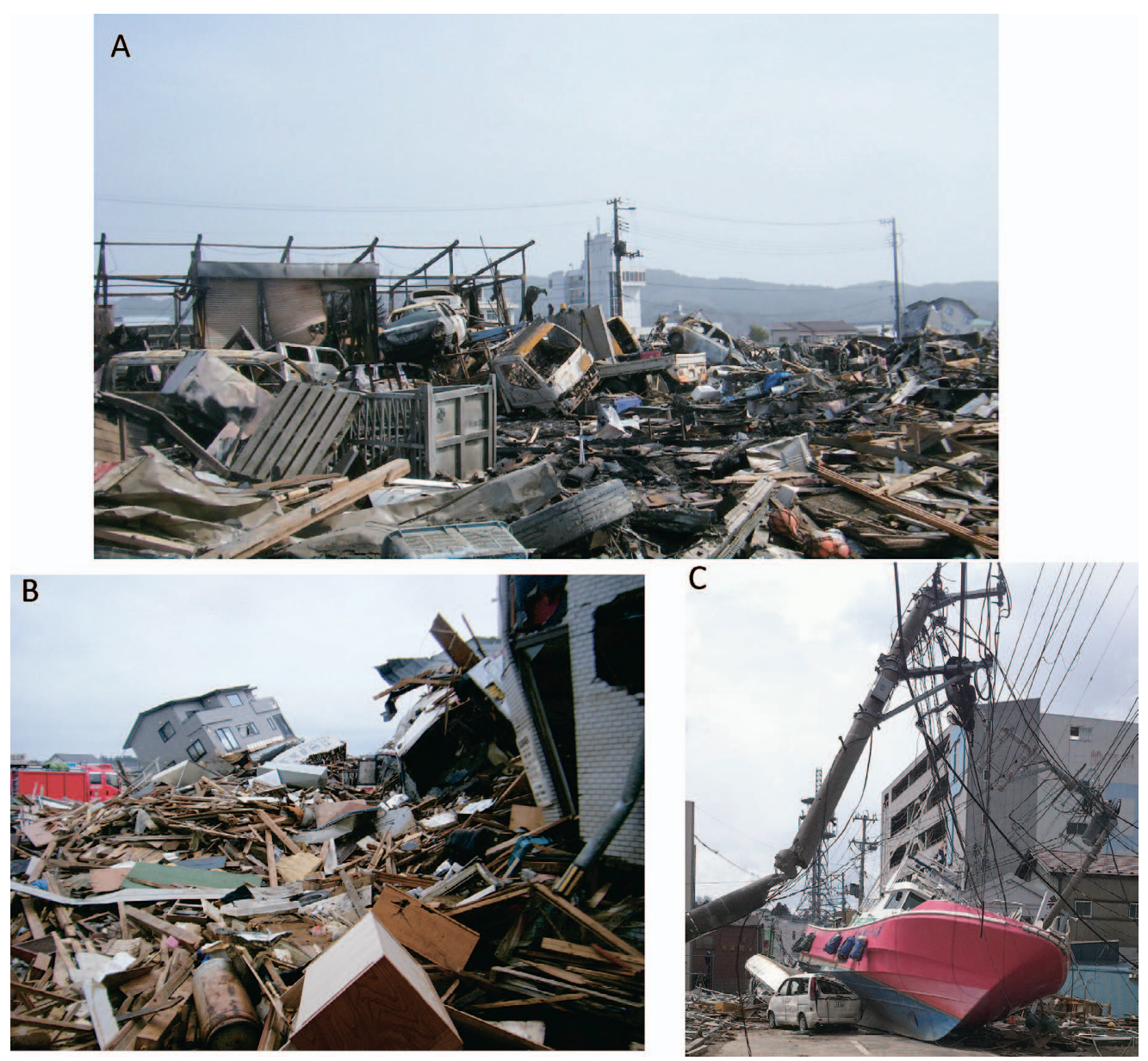

Fig. 3. Tsunami stricken-areas in Kesennuma and Ishinomaki.

A and B. Remnants of houses and debris in Kesennuma (Courtesy of Shin-Ichiro Osawa). C. A ship on the street in Ishinomaki (Courtesy of Ichiyo Shibahara).

Photos B and C were reprinted from Shibahara (2011), with permission of the Tohoku University Medical Press.

A

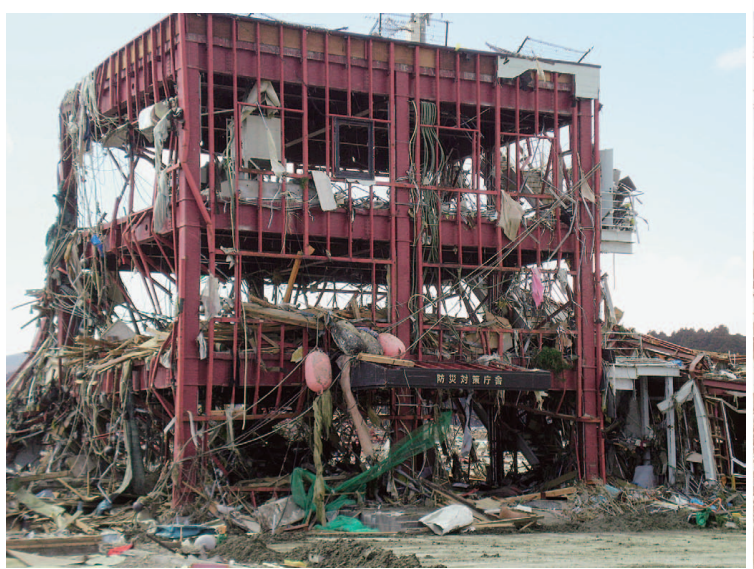

B

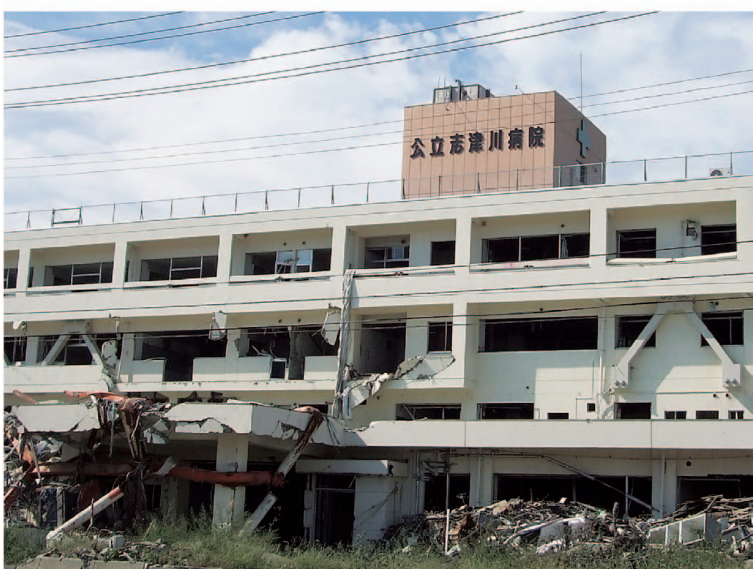

Fig. 4. Sorrowful remnants of the tsunami attack in Minami-Sanriku.

A. The three-story Minami-Sanriku municipal building for disaster-prevention measures destroyed by the March $11^{\text {th }}$ tsunami. Only the iron frame of the building remains. The Chinese characters at the entrance mean municipal building for disaster-prevention measures. The photo was taken on March 24, 2011 (Courtesy of Hitoshi Oshitani). The tsunami killed about 30 staff members who had evacuated to the roof of the building. A pole on the roof saved several persons. B. The four-story building of the Public Shizugawa Hospital. The tsunami reached the fourth floor of the two hospital buildings. The Chinese characters at the top mean The Public Shizugawa Hospital. The Public Shizugawa Hospital is located near the Minami-Sanriku municipal building (one block away). The photo was taken on September 18, 2011 (by T.S.). 
Table 3. Three prefectures of the Tohoku region with the worst damage by the 2011 tsunami

\begin{tabular}{|c|c|c|c|c|}
\hline Prefecture & City or (Town) & $\begin{array}{l}\text { Inundation Height } \\
\text { of Tsunami* }\end{array}$ & Dead persons $* *$ & Missing persons** \\
\hline \multirow{8}{*}{ Iwate } & Miyako & $7.3 \mathrm{~m}$ & 420 & 94 \\
\hline & (Yamada) & $9.7 \mathrm{~m}$ & 604 & 149 \\
\hline & (Otsuchi) & $12.6 \mathrm{~m}$ & 803 & 455 \\
\hline & Kamaishi & $9.3 \mathrm{~m}$ & 888 & 152 \\
\hline & Ofunato & $11.8 \mathrm{~m}$ & 340 & 80 \\
\hline & Rikuzentakata & $15.8 \mathrm{~m}$ & 1,556 & 217 \\
\hline & Others & & 61 & 22 \\
\hline & Subtotal & & 4,672 & 1,169 \\
\hline \multirow{13}{*}{ Miyagi } & Kesennuma & $12.0 \mathrm{~m}$ & 1,104 & 233 \\
\hline & (Minami-Sanriku) & $15.9 \mathrm{~m}$ & 594 & 223 \\
\hline & (Onagawa) & $14.8 \mathrm{~m}$ & 580 & 268 \\
\hline & Ishinomaki & $15.5 \mathrm{~m}$ & 3,256 & 448 \\
\hline & Higashi-Matsushima & $8.7 \mathrm{~m}$ & 1,061 & 28 \\
\hline & Tagajo & N/A & 188 & 0 \\
\hline & Sendai & $7.2 \mathrm{~m}$ & 654 & 30 \\
\hline & Natori & $9.1 \mathrm{~m}$ & 911 & 41 \\
\hline & Iwanuma & $8.8 \mathrm{~m}$ & 180 & 1 \\
\hline & (Watari) & $7.7 \mathrm{~m}$ & 251 & 6 \\
\hline & (Yamamoto) & N/A & 681 & 18 \\
\hline & Others & & 111 & 6 \\
\hline & Subtotal & & 9,571 & 1,302 \\
\hline \multirow{8}{*}{ Fukushima } & (Shinchi) & N/A & 100 & 10 \\
\hline & Soma & $8.9 \mathrm{~m}$ & 439 & 19 \\
\hline & Minami-Soma & N/A & 525 & 111 \\
\hline & (Namie) & N/A & 149 & 33 \\
\hline & Iwaki & N/A & 293 & 37 \\
\hline & Others & & 93 & 16 \\
\hline & Subtotal & & 1,599 & 226 \\
\hline & Total & & 15,842 & 2,697 \\
\hline
\end{tabular}

N/A: not available

Shown are cities and towns with large numbers of victims $(\geq 100)$ in the order of North to South. *Data shown are taken from the Japan Weather Association (http://www.jwa.or.jp/static/topics/20110422/tsunamigaiyou3.pdf); and **data shown from the reports of Iwate (as of February 28, 2013) (Iwate Bousai Jyoho Potal: http://www.pref.iwate.jp/ bousai/), Miyagi (as of February 28, 2013), and Fukushima (as of February 18, 2013). There are small differences in the numbers from those of Table 1 and Table 2, based on the report of March 11, 2013 by the National Police Agency (http://www.npa. go.jp/archive/keibi/biki/index_e.htm).

saved many lives of inpatients by transporting them to the fifth floor through the stairs before the tsunami arrived.

On the other hand, some people did not properly evacuate after the 2011 Earthquake, despite the 50-min interval between the Earthquake and the tsunami's arrival. The Okawa Elementary School is located in a rural area of Ishinomaki City, Miyagi, near the end of the Kitakami River (Fig. 5), the area of which has been characterized by depopulation. The tragedy was the loss of 74 of the 108 children in the Okawa Elementary School. They, together with 11 teachers, had evacuated to the school ground and remained there until the tsunami arrived, although there is a steep hill just behind the Okawa Elementary School. It is currently under investigation why the teachers did not evacuate the children to the hill. Obviously, those teachers did not expect the attack of the tsunami in part due to the fact that the school is $4 \mathrm{~km}$ away from the Pacific Ocean. In addition, the Okawa Elementary School had been appointed as an evacuation center. However, the March $11^{\text {th }}$ tsunami attacked the school through the Kitakami River at 15:37, judged by the broken clocks (MEMORY EVERDAISHINSAI: http://memory.ever.jp/tsunami/higeki_bosaityosya.html). Nine out of the 11 teachers were also killed by the tsunami. Four children and one teacher are still 


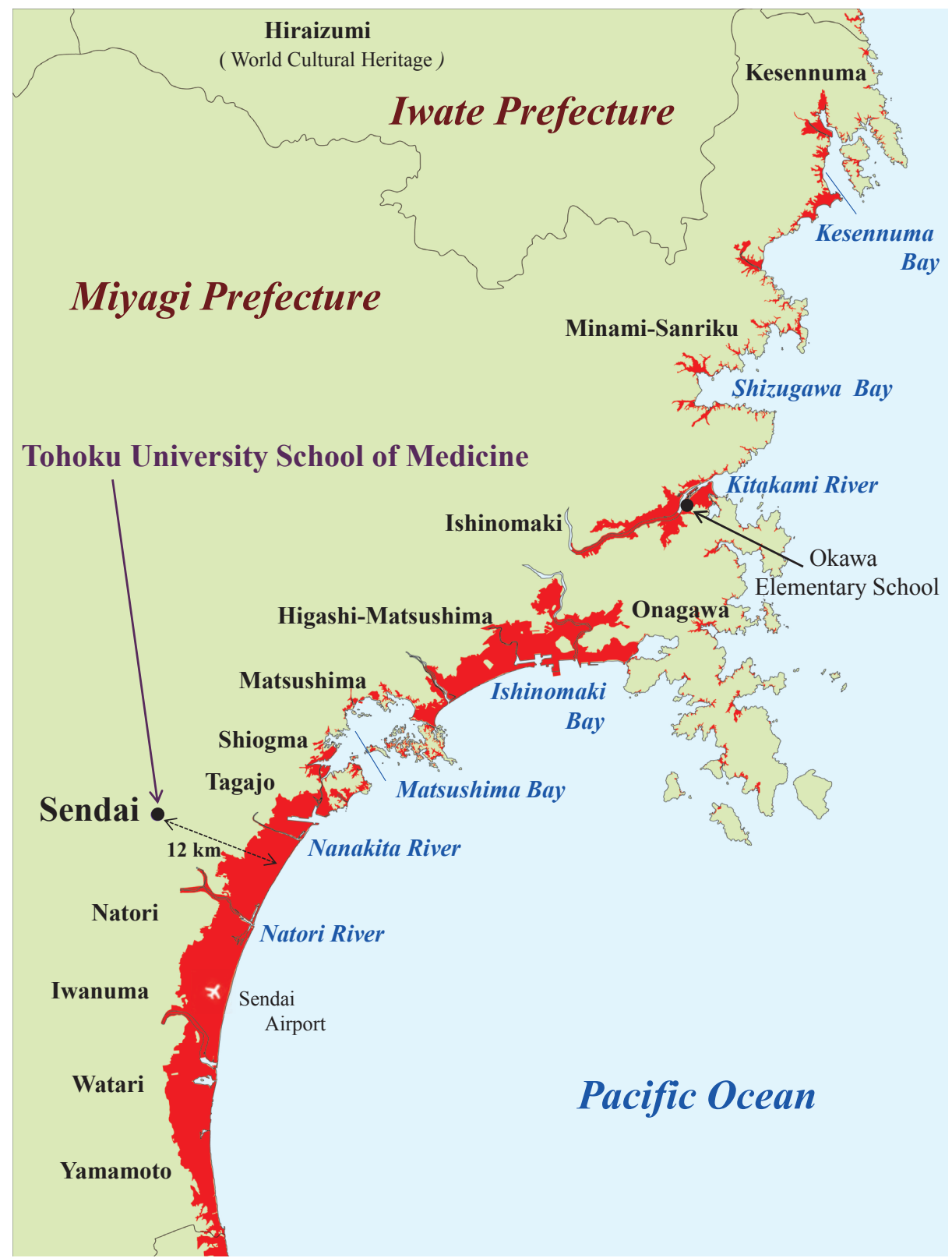

Fig. 5. Tsunami-inundated areas of the Sendai plain.

The tsunami-inundated areas of the Sendai plain in the Miyagi prefecture are marked in red. Cities and towns with large numbers of victims $(\geq 100)$ are shown (see Table 3). Note that the Okawa Elementary School is located in the tsunamiinundated areas along the Kitakami River. In contrast, the tsunami did not severely invade the Matsushima coast, one of three famous sights of Japan. The location of the Tohoku University School of Medicine is indicated.

missing. Because of a small number of graduates from the Okawa Elementary School, the Okawa Junior High School was closed in March 2013. We should remember that the river is a route of tsunami invasion (Fig. 5).

The historical document of Japan, Nihon Sandai Jitsuroku, indicates that a large-scale earthquake and subsequent tsunami attacked the northeast Japan on July 13, 869, resulting in the loss of 1,000 lives (Minoura et al. 2001). The tsunami in the year of 869 was named the Jogan tsunami, after the name of the emperor at the time. Analyzing the tsunami deposits, Minoura and colleagues concluded that the distance of seawater inundation by the Jogan tsunami was about $2.5 \mathrm{~km}$ inland from the present coast of the Sendai plain (Minoura et al. 2001). They estimated the recurrence interval of a large-scale tsunami as 800 to 1,000 years. However, this historical fact was almost completely unknown, which makes us aware of the vital importance of widely disseminating the records of current disasters (Shibahara 2011, 2012). In fact, with advancing urbanization, the seacoast areas inundated by the Jogan tsunami have been developed as residential areas. Unfortunately, many of the towns developed in those areas were reached 
by the March $11^{\text {th }}$ tsunami (areas shown in red, Fig. 5), such as Natori, Iwanuma, Watari and Yamamoto. Most residents in the coastal areas of the Sendai plain did not know that a tsunami had visited their residential areas about 1,000 years earlier, resulting in the largest number of victims in the Miyagi prefecture $(9,536$ dead and 1,302 missing persons, Table 2). It is noteworthy that the many small islands distributed in Matsushima Bay appeared to weaken the power of the tsunami, as evident from the restricted indurated area of Matsushima, one of three famous sights in Japan (Fig. 5).

The March $11^{\text {th }}$ tsunami also attacked the seacoast areas of the Soma plain in the Fukushima prefecture, including Soma and Iwaki cities and the Fukushima DaiIchi Nuclear Power Plant (see Fig. 1). According to the Japan Meteorological Agency, the height of the tsunami was $9.3 \mathrm{~m}$ in Soma (Table 2).

\section{Tragedy in Fukushima}

Fukushima was attacked by the triple disaster on March 11, 2011: earthquake, tsunami and radioactive releases. As evident from many reports listed in PubMed, the worldwide concern is the environmental contamination with radioactive substances due to the accident of the Fukushima Dai-Ichi Nuclear Power Plant (Stohl et al. 2011; Kinoshita et al. 2011; Yasunari et al. 2011; Brumfiel and Fuyuno 2012; Madigan et al. 2012; Batsford 2013). Indeed, the released radioactive substances contaminated soils and the ocean (Kinoshita et al. 2011; Yasunari et al. 2011; Bailly du Bois et al. 2012; Tsumune et al. 2012; Buesseler et al. 2012). Relevant information is also available from the Ministry of Education, Culture, Sports, Science and Technology, Japan (http://radioactivity.mext.go.jp/en/), Tokyo Electric Power Company (http://www.tepco.co.jp/en/ nu/fukushima-np/review/index-e.html), and the World Health Organization (http://www.who.int/ionizing_radiation/pub_meet/fukushima_dose_assessment/en/index.html).

Among radioactive substances released from the Fukushima Dai-Ichi Nuclear Power Plant, people are especially worried about the thyroid accumulation of Iodine-131 ( ${ }^{131}$ I, with a half-life of 8 days) (Kamada et al. 2012; Tokonami et al. 2012) and the health risk of Cesium-137 $\left({ }^{137} \mathrm{Cs}\right)$ because of its long half-life of 30 years (Calabrese 2011). Tokonami et al. (2012) detected ${ }^{131}$ I activity in the thyroid of 46 out of the 62 residents and evacuees measured during April 12-16, 2011. They estimated the median thyroid equivalent dose to be $4.2 \mathrm{mSv}$ and $3.5 \mathrm{mSv}$ for children (under 20 years) and adults, respectively. The estimated dose was much smaller than the mean thyroid dose (490 mSv) measured in evacuees of the Chernobyl accident (Tokonami et al. 2012). Recently, Fukuda et al. (2013) showed the deposition of ${ }^{137} \mathrm{Cs}$ and ${ }^{134} \mathrm{Cs}$ with a half-life of 2 years in all organs of 79 cattle abandoned in the evacuation zone, a $20-\mathrm{km}$ radius around the Fukushima Dai-Ichi Nuclear Power Plant, with the highest accumulation in the skeletal muscle. Samples analyzed were collected between August 29 and November 15, 2011. In contrast to Cs, they also found the organ-specific deposition of silver- $110 \mathrm{~m}$ $\left({ }^{110 \mathrm{~m}} \mathrm{Ag}\right.$, with a half-life of 249.8 days) and tellurium- $129 \mathrm{~m}$ ( ${ }^{129 \mathrm{~m}} \mathrm{Te}, 33.6$ days): ${ }^{110 \mathrm{~m}} \mathrm{Ag}$ in the liver and the blood and ${ }^{129 \mathrm{~m}} \mathrm{Te}$ only in the kidney (Fukuda et al. 2013). Long-term follow-up studies from various aspects are required for the restoration of Fukushima.

The critical situation of Fukushima is also apparent from the fact that about 57,000 people have evacuated to other prefectures (as of February 7, 2013). In addition, about 100,000 people have moved to other areas of the Fukushima prefecture. There are many families who are being forced to live separately to protect their children from radioactive materials. Thus, Fukushima is faced with longterm depopulation due to the health risk caused by the deposition of radionuclides (Ishikawa et al 2012). We extend our heartfelt sympathy to all people who were affected by this earthquake and tsunami and by the subsequent nuclear radiation from damaged reactors in Fukushima.

Current health conditions of people living in the 2011 disaster-stricken areas

Since March 11, 2011, many people living in coastal areas of the Tohoku region feel profound sadness due to the loss of families, friends, jobs, houses and/or communities. In addition, many of those people are elderly (aged 65 years or over) and have large amounts of financial burden as well as psychological stress. In fact, after the Great East-Japan Earthquake, there have been reports showing the increased prevalence or worsening of various diseases, including influenza infection (Hatta et al. 2012; Tohma et al. 2012), chronic obstructive pulmonary disease (Yamanda et al. 2013), pneumonia (Suzuki et al. 2011; Aoyagi et al. 2012; Takahashi et al. 2012; Daito et al. 2013), near drowningassociated fungal infection (Nakamura et al. 2011; Igusa et al. 2012; Kawakami et al. 2012), diabetes mellitus (Fujihara et al. 2012), hypertension (Ogawa et al. 2012), cardiovascular diseases (Aoki et al. 2012), heart failure (Nakano et al. 2012), deep vein thrombosis (Ueda et al. 2012; Shibata et al. 2013), peptic ulcers (Kanno et al. 2012), dementia (Furukawa et al. 2012), and seizure (Shibahara et al. 2013). The increased onset or worsening of these diseases may be related to life-threatening stress, depressive situations without future prospects, or unhealthy conditions in the evacuation centers and/or subsequent temporary housing. In fact, psychological stress induced by the earthquake was associated with an increase in salivary cortisol levels (Kotozaki and Kawashima 2012) and possibly with structural changes in the brain (Sekiguchi et al. 2012).

Many papers have reported increases in respiratory diseases, which may be related to the high population of elderly people in the tsunami-stricken areas (Suzuki et al. 2011; Daito et al. 2013; Yamanda et al. 2013). It is of particular importance to take care of elderly evacuees, because they may not complain of problems, as observed in the 1995 Great Hanshin-Awaji Earthquake (Morimoto et al. 
2011). In this connection, the male suicide rate was significantly decreased in Kobe after the Great Hanshin-Awaji Earthquake (Shioiri et al. 1999) and in the Niigata prefecture after the Niigata-Chuetsu earthquake occurred on October 23, 2004 (Hyodo et al. 2010). The Niigata-Chuetsu earthquake (magnitude 6.8) resulted in the deaths of 68 persons. However, in the case of the Great East-Japan Earthquake, an enormous number of people are still suffering from the tragic consequences of the triple disaster, the conditions of which have never been experienced in any country. Long-term follow-up and support is required for people living in the disaster-affected areas.

Another critical issue is a shortage of physicians in the Tohoku region. Tsunami destroyed many hospitals and clinics in the coastal areas, thereby enhancing the movement of physicians and other healthcare professionals from the disaster-stricken areas. Indeed, public health systems were severely damaged and are not fully functioning yet in many affected areas. Accordingly, in collaboration with Tohoku University Hospital, the Tohoku University Graduate School of Medicine has pursued a range of activities that assist with the restoration or new construction of medical services in the affected areas. For example, the Tohoku University Graduate School of Medicine established the Center for Community Health on May 1, 2011 to provide support to the local communities in the Miyagi prefecture that were affected by the Great East Japan Earthquake (Director, Ichiro Tsuji; http://www.ch-center. med.tohoku.ac.jp/english). It is urgent to reconstruct the local public health systems for protecting lives and health of survivors and also for recovery of the communities. The center has been implementing a project to document public health recovery processes in Miyagi prefecture, especially in two areas of Ishinomaki city, Oshika and Ogatsu (Doran et al. 2013). The report was presented at the International Symposium on Public Health Recovery after the Great East Japan Earthquake, which was conducted from March 7-8, 2013 in Sendai. In addition, the Tohoku University Graduate School of Medicine has established the Comprehensive Training Center for Community Medicine (Director, Hideo Harigae) to provide the network for retraining physicians and medical professionals of the stricken area and to nurture those people who will play a leading role in community medicine and the new disaster medical care. The Tohoku University Hospital, the Graduate School of Dentistry and the Institute of Development, Aging and Cancer are also responsible for achieving the goal of the Comprehensive Training Center for Community Medicine.

\section{Back to the Great Kanto Earthquake in 1923}

On September 1, 1923, the magnitude-7.9 Great Kanto Earthquake struck the Kanto region at lunchtime (11:58:44) when many people were cooking meals over a fire or with a charcoal stove, causing fires at multiple sites. Its epicenter was $80 \mathrm{~km}$ off the Sagami Bay (see Fig. 1). Multiple onsets of large fires developed into firestorms that swept across cities, including Tokyo. About 105,000 deaths and missing persons were recorded in the Kanto region, including Tokyo, Chiba, and Yokohama (Table 1). Most of the victims were killed by fire. The Great Kanto Earthquake did not directly damage the city of Sendai. However, fire destroyed the Tsukiji Printing Office in Tokyo that printed every issue of the TJEM since 1920. Under such difficult situations, the founding Editors of the TJEM were able to publish the three issues of 1923 (Vol. 4 Nos. 4-6) in 1924, thanks to the collaboration between the Tohoku Imperial University and the Wistar Institute, Philadelphia, PA, USA (Shibahara 2009). Moreover, three issues of 1924 (Vol. 5 Nos. 1-3) were also published in Philadelphia by courtesy of the Wistar Institute (Fig. 6A). Accordingly, the TJEM has been published continuously despite the 1923 Great Kanto Earthquake.

On the other hand, for contributors to the TJEM, it took a long time to publish the papers submitted in 1923 , because the large fire also burnt the accepted manuscripts kept in the Tsukiji Printing Office. In fact, one author described in a footnote that the publication was delayed due to the fire of the Tsukiji Printing Office in Tokyo (Kodama 1924) (Fig. 6B). We would like to express our deep gratitude to the Wistar Institute for printing the TJEM issues of 1923 and 1924 and to the contributors for their patience.

Currently, all articles of the TJEM (from 1920 to present) are freely available in electronic version to everyone through the "Japan Science and Technology Information Aggregator, Electronic" (J-STAGE: https://www.jstage.jst. go.jp/browse/tjem), developed by the Japan Science and Technology Agency. Accordingly, even after the Great East-Japan Earthquake, the online submission and publication systems were properly maintained in Tokyo, and thus the online version of the April 2011 issue (Vol. 223 No. 4) was completed on April 9, 2011 without delay. In contrast, the printed version of the March issue was published on April 27, delayed nearly two months, because the earthquake had damaged the print machine of Sasaki Printing \& Publishing Co. Ltd., located in Sendai. Online publication is an effective method during natural disasters. It is better for every publisher to have two options of publication in distant cities: online and printed publication. These two publication methods are mutually complementary to maintain on-time publication during natural disasters. Taken together, we would like to emphasize the importance of the mutual aid relationship between cities in distant sites to support the lives of residents upon natural disasters.

\section{Moving forward on the Creative Restoration from the Great East-Japan Earthquake}

Thanks to the quake-resistant and quake-absorbing buildings along with good fortune, there were no deaths or injuries among students and employees in all campuses of the Tohoku University (Normile 2011; Shibahara 2012). Even under the full-scale blackout after the earthquake, the 
A

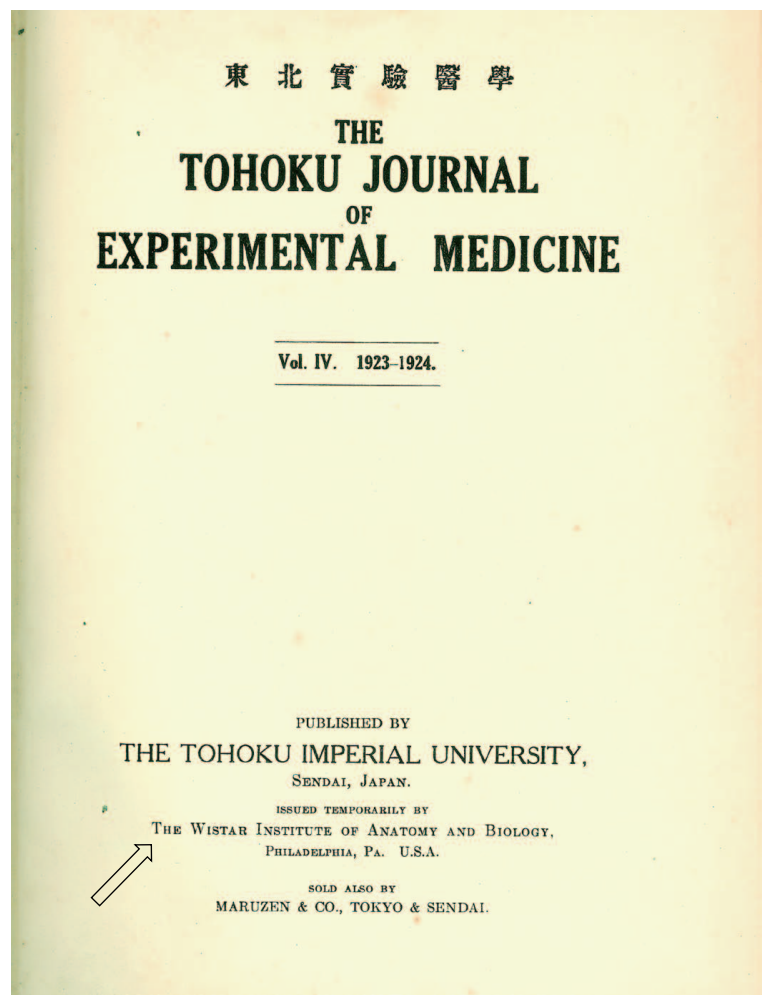

$\mathrm{B}$

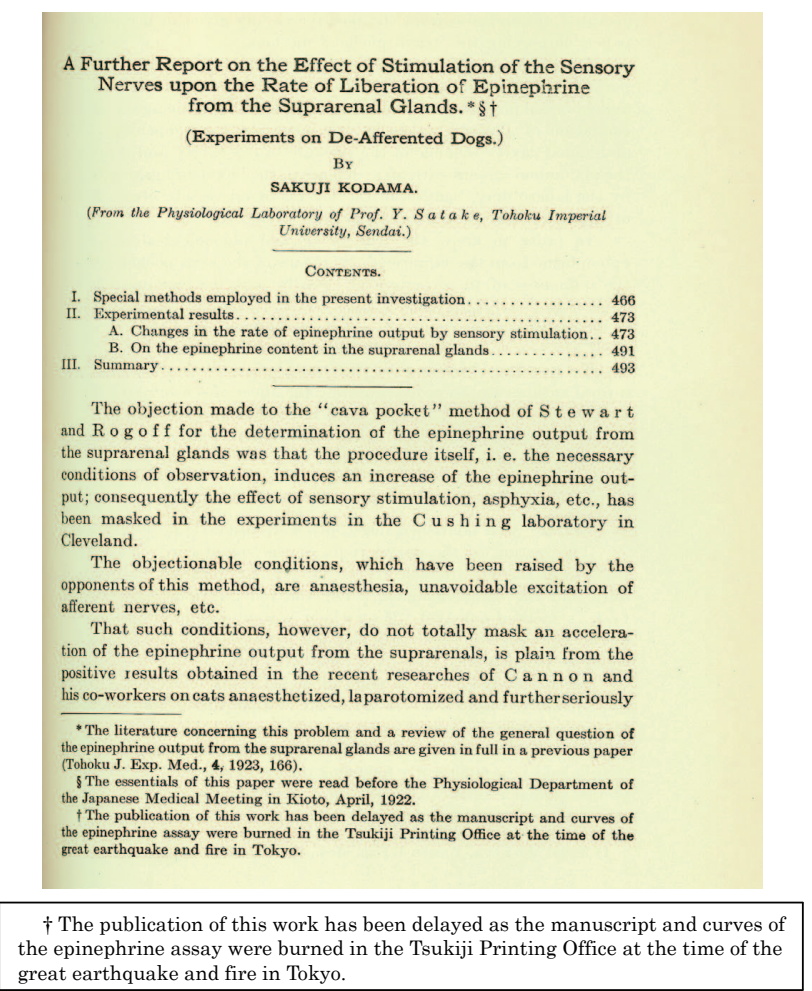

Fig. 6. Support by the Wistar Institute following the Great Kanto Earthquake in 1923.

A. Top page of Volume 4 published by the Wistar Institute (arrow). The Japanese translation of TJEM (Tohoku Jikken Igaku) is shown at the top of the cover page. Note that the TJEM was sold by a book and trading company, Maruzen, as shown at the bottom of the cover page (Shibahara 2009). B. Delayed publication of a paper accepted in 1923. The fire evoked by the 1923 Great Kanto Earthquake destroyed the accepted manuscripts of the TJEM, kept in the Tsukiji Printing Office, Tokyo. The relevant text is enlarged at bottom.

Tohoku University Hospital (1,308 beds) retained most of the ordinary functions with its own electric power system (Shibahara 2011; Satomi 2011; Yambe et al. 2012). Accordingly, the Tohoku University Hospital plays an important role for supporting hospitals and clinics in tsunami-stricken areas (Satomi 2011). On the other hand, the earthquake damaged many buildings and instruments of the Tohoku University. More seriously, the earthquake and the subsequent blackout resulted in the loss of enormous numbers of irreplaceable specimens, such as blood samples and tumor tissues. Even under such severe circumstances, the Tohoku University School of Medicine/Graduate School of Medicine started to move forward immediately after March 11 on the restoration. Relevant articles were published for students, researchers, librarians, and others living in earthquake-prone zones (Osumi 2011; Meguro 2011; Sakamoto et al. 2011; Shibahara 2012). Moreover, the Tohoku University School of Medicine/Graduate School of Medicine (2012) published the records of the Great EastJapan Earthquake (in Japanese) that summarize the efforts of the faculty on the restoration of the education and on the medical assistant in the tsunami-stricken areas. The online version is freely available from the website (http://ir.library. tohoku.ac.jp/re/handle/10097/54278) or (http://www.med. tohoku.ac.jp/d_report/index.html). In fact, the faculty and graduates, in collaboration with the Tohoku University Hospital, responded rapidly to provide medical assistance and to contribute to restoration of the affected areas.

On the other hand, Tohoku University has established an International Research Institute for Disaster Science that aims to reduce or avoid potential losses from natural hazards, to assure prompt assistance to victims, to achieve rapid and effective recovery, and to build disaster-resilient and sustainable societies (Director, Arata Hirakawa; http:// irides.tohoku.ac.jp/eng/index.html). Moreover, to foster the reconstruction of the Tohoku region, Tohoku University has established the Tohoku Medical Megabank Organization (Executive Director, Masayuki Yamamoto; http://www. megabank.tohoku.ac.jp/english/index.php).

Immediately after the Great East-Japan Earthquake, many institutions around the world, including the National Institutes of Health (NIH), offered generous assistance for scientists at the Tohoku University, by providing them with an opportunity to continue their research at their respective institutions. Accordingly, some researchers of the Tohoku University, whose laboratories were damaged by the earthquake, were able to continue their research work at NIH. In this context, NIH and Tohoku University have a long his- 
tory of research collaborations. For example, many faculty members of Tohoku University, including Noriaki Ohuchi, Dean, Tohoku University School of Medicine, have worked at NIH.

On the occasion of the $2^{\text {nd }}-$ Year Anniversary of the Great East-Japan Earthquake, Tohoku University is organizing an international symposium on May 9-10, 2013 in Sendai by collaborating with NIH and the Japan Society for the Promotion of Science (JSPS). The goal of the "NIHTohoku University-JSPS Symposium" is to further strengthen research collaboration between NIH and Tohoku University. This international collaborative initiative will support the ongoing recovery effort in the affected areas for future by promoting biomedical research in the Tohoku area. The upcoming "NIH-Tohoku University-JSPS Symposium" is fully supported by Dr. Michael Gottesman, Deputy Director for Intramural Research at NIH, by Dr. Susumu Satomi, President, Tohoku University, and by Dr. Osamu Shimomura, Director, JSPS Washington DC Office. The detailed information is available at the website $(\mathrm{NIH}-$ Tohoku University-JSPS Symposium: http://www.med. tohoku.ac.jp/english/nih2013/).

\section{Concluding remarks}

Every house and building should be constructed in a quake-absorbing or quake-resistant structure, ideally with its own electric power system. Because fires or tsunami accompanied past Great Earthquakes in Japan, it is important for many cities to design preventive strategies against both fires and tsunami. In addition, mutual aid relationships should be established between distant communities or cities. Lastly, we would like to recommend the mindset of individual evacuation, "Tsunami, ten-den-ko," for people living in coastal areas of earthquake-prone zones around the world.

As residents of Sendai, we would like to express our heartfelt gratitude to many teams from all over Japan and the foreign countries for their kind and warm support to people living in the Tohoku region. We believe the powerful resilience of the people living in the disaster-stricken areas.

\section{Acknowledgements}

The TJEM is published with generous support by the Grantin-Aid for Publication of Scientific Research Results from the Japan Society for the Promotion of Science. The TJEM is grateful to many contributors and referees, J-STAGE, and the Japan Society for the Promotion of Science. We also thank the Wistar Institute for publishing Volumes 4 and 5 of the TJEM that include six issues of 1923 and 1924. Lastly, we thank Sasaki Printing \& Publishing Co. Ltd. and Mr. Susumu Kawamata for their efforts in achieving on-time publication of the April 2011 issue.

\section{Conflict of Interest}

The authors declare no conflict of interest.

\section{References}

Aoki, T., Fukumoto, Y., Yasuda, S., Sakata, Y., Ito, K., Takahashi, J., Miyata, S., Tsuji. I. \& Shimokawa, H. (2012) The Great East Japan Earthquake Disaster and cardiovascular diseases. Eur. Heart J., 33, 2796-2803.

Aoyagi, T., Yamada, M., Kunishima, H., Tokuda, K., Yano, H., Ishibashi, N., Hatta, M., Endo, S., Arai, K., Inomata, S., Gu, Y., Kanamori, H., Kitagawa, M., Hirakata, Y. \& Kaku, M. (2012) Characteristics of infectious diseases in hospitalized patients during the early phase after the 2011 Great East Japan earthquake: pneumonia as a significant reason for hospital care. Chest, 143, 349-356.

Bailly du Bois, P., Laguionie, P., Boust, D., Korsakissok, I., Didier, D. \& Fiévet, B. (2012) Estimation of marine source-term following Fukushima Dai-ichi accident. J. Environ. Radioact., 114, 2-9.

Batsford, S. (2013) The Great East Japan Earthquake and Tsunami Viewed from Western Europe: How has Fukushima influenced the peaceful use of atomic energy in Europe? Tohoku J. Exp. Med., 229, 239-244.

Brumfiel, G. \& Fuyuno, I. (2012) Japan's nuclear crisis: Fukushima's legacy of fear. Nature, 483, 138-140.

Buesseler, K., Aoyama, M. \& Fukasawa, M. (2011) Impacts of the Fukushima Nuclear Power Plants on marine radioactivity. Environ. Sci. Technol., 45, 9931-9935.

Buesseler, K.O., Jayne, S.R., Fisher, N.S., Rypina, I.I., Baumann, H., Baumann, Z., Breier, C.F., Douglass, E.M., George, J., Macdonald, A.M., Miyamoto, H., Nishikawa, J., Pike, S.M. \& Yoshida, S. (2012) Fukushima-derived radionuclides in the ocean and biota off Japan. Proc. Natl. Acad. Sci. USA, 109, 5984-5988.

Calabrese, E. (2011) Improving the scientific foundations for estimating health risks from the Fukushima incident. Proc. Natl. Acad. Sci. USA, 108, 19447-19448.

Daito, H., Suzuki, M., Shiihara, J., Kilgore, P.E., Ohtomo, H., Morimoto, K., Ishida, M., Kamigaki, T., Oshitani, H., Hashizume, M., Endo, W., Hagiwara, K., Ariyoshi, K. \& Okinaga, S. (2013) Impact of the Tohoku earthquake and tsunami on pneumonia hospitalisations and mortality among adults in northern Miyagi, Japan: a multicentre observational study. Thorax, [Epub ahead of print].

Doran, R., Oshitani, H., Kamigaki, T., Mimura, S., Sato, M., Tamamura, B. \& Nishina, T. (2013) Public Health Recovery after the Great East Japan Earthquake: experiences in selected areas of Miyagi Prefecture. Center for Community Health, Tohoku University Graduate School of Medicine, Sendai, Miyagi. 94p.

Fujihara, K., Saito, A., Heianza, Y., Gibo, H., Suzuki, H., Shimano, H., Saito, K., Kodama, S., Yamada, N. \& Sone, H. (2012) Impact of psychological stress caused by the Great East Japan earthquake on glycemic control in patients with diabetes. Exp. Clin. Endocrinol. Diabetes, 120, 560-563.

Fukuda, T., Kino, Y., Abe, Y., Yamashiro, H., Kuwahara, Y., Nihei, H., Sano, Y., Irisawa, A., Shimura, T., Fukumoto, M., Shinoda, H., Obata, Y., Saigusa, S., Sekine, T., Isogai, E. \& Fukumoto, M. (2013) Distribution of artificial radionuclides in abandoned cattle in the evacuation zone of the Fukushima Daiichi Nuclear Power Plant. PLoS One, 8, e54312.

Furukawa, K. \& Arai, H. (2011) Earthquake in Japan. Lancet, 377, 1652.

Furukawa, K., Ootsuki, M., Kodama, M. \& Arai, H. (2012) Exacerbation of dementia after the earthquake and tsunami in Japan. J. Neurol., 259, 1243

Garnier-Laplace, J., Beaugelin-Seiller, K. \& Hinton, T.G. (2011) Fukushima wildlife dose reconstruction signals ecological consequences. Environ. Sci. Technol., 45, 5077-5078.

Hatta, M., Endo, S., Tokuda, K., Kunishima, H., Arai, K., Yano, H., 
Ishibashi, N., Aoyagi, T., Yamada, M., Inomata, S., Kanamori, H., Gu, Y., Kitagawa, M., Hirakata, Y. \& Kaku, M. (2012) Post-tsunami outbreaks of influenza in evacuation centers in Miyagi Prefecture, Japan. Clin. Infect. Dis., 54, e5-7.

Hyodo, K., Nakamura, K., Oyama, M., Yamazaki, O., Nakagawa, I., Ishigami, K., Tsuchiya, Y. \& Yamamoto, M. (2010) Longterm suicide mortality rates decrease in men and increase in women after the Niigata-Chuetsu Earthquake in Japan. Tohoku J. Exp. Med., 220, 149-155.

Igusa, R., Narumi, S., Murakami, K., Kitawaki, Y., Tamii, T., Kato, M., Sato, M., Tsuboi, M. \& Ota, K. (2012) Escherichia coli pneumonia in combination with fungal sinusitis and meningitis in a tsunami survivor after the Great East Japan Earthquake. Tohoku J. Exp. Med., 227, 179-184.

Ishikawa, K., Kanazawa, Y., Morimoto, S. \& Takahashi, T. (2012) Depopulation with rapid aging in Minamisoma City after the Fukushima Daiichi nuclear power plant accident. J. Am. Geriatr. Soc., 60, 2357-2358.

Iwate Bousai Jyoho Potal. http://www.pref.iwate.jp/ bousai/ [Accessed: March 27, 2013].

Japan Meteorological Agency. http://www.seisvol.kishou.go.jp/eq/ higai/higai-1995.html.

http://www.seisvol.kishou.go.jp/eq/2011_03_11_tohoku/ index.html [Accessed: March 27, 2013].

Japan Weather Association. http://www.jwa.or.jp/static/ topics/20110422/tsunamigaiyou3.pdf [Accessed: March 27, 2013].

Kamada, N., Saito, O., Endo, S., Kimura, A. \& Shizuma, K. (2012) Radiation doses among residents living $37 \mathrm{~km}$ northwest of the Fukushima Dai-ichi Nuclear Power Plant. J. Environ. Radioact., 110, 84-89.

Kanno, T., Iijima, K., Abe, Y., Koike, T., Shimada, N., Hoshi, T., Sano, N., Ohyauchi, M., Ito, H., Atsumi, T., Konishi, H., Asonuma, S. \& Shimosegawa, T. (2012) Peptic ulcers after the Great East Japan earthquake and tsunami: possible existence of psychosocial stress ulcers in humans. J. Gastroenterol., [Epub ahead of print].

Kawakami, Y., Tagami, T., Kusakabe, T., Kido, N., Kawaguchi, T., Omura, M. \& Tosa, R. (2012) Disseminated aspergillosis associated with tsunami lung. Respir. Care, 57, 1674-1678.

Kinoshita, N., Sueki, K., Sasa, K., Kitagawa, J., Ikarashi, S., Nishimura, T., Wong, Y.S., Satou, Y., Handa, K., Takahashi, T., Sato, M. \& Yamagata, T. (2011) Assessment of individual radionuclide distributions from the Fukushima nuclear accident covering central-east Japan. Proc. Natl. Acad. Sci. USA, 108, 19526-19529.

Kodama, S. (1924) A further report on the effect of stimulation of the sensory nerves upon the rate of liberation of epinephrine from the suprarenal glands: experiments on de-afferented dogs. Tohoku J. Exp. Med., 4, 465-493.

Kotozaki, Y. \& Kawashima, R. (2012) Effects of the HigashiNihon earthquake: posttraumatic stress, psychological changes, and cortisol levels of survivors. PLoS One, 7, e34612.

Madigan, D.J., Baumannb, Z. \& Fisher, N.S. (2012) Pacific bluefin tuna transport Fukushima-derived radionuclides from Japan to California. Proc. Natl. Acad. Sci. USA, 109, 9483-9486.

Meguro, K. (2011) Local response following the Great East Japan Earthquake 2011. Neurology, 77, e12-15.

MEMORY EVER-DAISHINSAI. Bousai taisaku chosya no higeki: Miyagi • Minamisariku. http://memory.ever.jp/tsunami/ higeki bosai-tyosya.html [Accessed: March 27, 2013].

Ministry of Education, Culture, Sports, Science and Technology (MEXT). Monitoring information of environmental radioactivity level. [Cited: September 19, 2012]. http://radioactivity. mext.go.jp/en/ [Accessed: March 27, 2013].

Minoura, K., Imamura, F., Sugawara, D., Kono, Y. \& Iwashita, T. (2001) The 869 Jogan tsunami deposit and recurrence interval of large-scale tsunami on the Pacific coast of northeast Japan.
J. Natural Disaster Sci., 23, 83-88.

Morimoto, S., Iijima, K., Kuzuya, M., Hattori, H., Yokono, K. \& Takahashi, T. (2011) Guidelines for non-medical care providers to detect illnesses in elderly evacuees after the 2011 earthquake off the Pacific coast of Tohoku. J. Am. Geriatr. Soc., 59, 2189-2191.

Nakamura, Y., Utsumi, Y., Suzuki, N., Nakajima, Y., Murata, O., Sasaki, N., Nitanai, H., Nagashima, H., Miyamoto, S., Yaegashi, J., Hatakeyama, T., Shibano, Y., Yarita, K., Kamei, K., Nakadate, T., Endo, S., Terayama, Y. \& Yamauchi, K. (2011) Multiple Scedosporium apiospermum abscesses in a woman survivor of a tsunami in northeastern Japan: a case report. J. Med. Case Rep., 5, 526.

Nakano, M., Kondo, M., Wakayama, Y., Kawana, A., Hasebe, Y., Shafee, M.A., Fukuda, K. \& Shimokawa, H. (2012) Increased incidence of tachyarrhythmias and heart failure hospitalization in patients with implanted cardiac devices after the great East Japan earthquake disaster. Circ. J., 76, 1283-1285.

National Police Agency. Countermeasures for the Great East Japan Earthquake (NPA). http://www.npa.go.jp/archive/keibi/biki/ index_e.htm [Accessed: March 27, 2013].

NIH-Tohoku University-JSPS Symposium. [Cited: March 11, 2013]. http://www.med.tohoku.ac.jp/english/nih2013/ [Accessed: March 27, 2013].

Normile, D. (2011) Japan disaster. Picking up the pieces at ravaged Tohoku University. Science, 333, 153-155.

Ogawa, S., Ishiki, M., Nako, K., Okamura, M., Senda, M., Sakamoto, T. \& Ito, S. (2012) Effects of the Great East Japan Earthquake and huge tsunami on glycaemic control and blood pressure in patients with diabetes mellitus. BMJ Open, 2, e000830.

Osumi, N. (2011) Life science must go on: standing up after the 311 disaster. Genes Cells, 16, 741-744.

Sakamoto, K., Minamidate, Y. \& Nagai, T. (2011) Messages from a medical library in the earthquake-prone zone. Tohoku $J$. Exp. Med., 225, 77-80.

Satake, K., Namegaya, Y. \& Yamaki, S. (2008) Numerical simulation of the AD 869 Jogan tsunami in Ishinomaki and Sendai plains: Katsudanso-Kojishin Kenkyu Houkoku. Active FaultAncient Earthquake Research Reports, No. 8, pp. 71-89. (in Japanese with English abstract).

Satomi, S. (2011) The Great East Japan Earthquake: Tohoku University Hospital's efforts and lessons learned. Surg. Today, 41, 1171-1181.

Schiermeier, Q. (2011) Radiation release will hit marine life. Nature, 472, 145-146.

Sekiguchi, A., Sugiura, M., Taki, Y., Kotozaki, Y., Nouchi, R., Takeuchi, H., Araki, T., Hanawa, S., Nakagawa, S., Miyauchi, C.M., Sakuma, A. \& Kawashima, R. (2012) Brain structural changes as vulnerability factors and acquired signs of postearthquake stress. Mol. Psychiatry, [Epub ahead of print].

Sekine, R. (2011) Did the People Practice "Tsunami Tendenko"?The reality of the 3.11 tsunami which attacked Shizugawa Area, Minamisanriku Town, Miyagi Prefecture: the 2011 East Japan Earthquake Bulletin of the Tohoku Geographical Association. http://tohokugeo.jp/disaster/articles/e-contents22.html [Accessed: March 27, 2013].

Shibahara, I., Osawa, S.I., Kon, H., Morita, T., Nakasato, N., Tominaga, T. \& Narita, N. (2013) Increase in the number of patients with seizures following the Great East-Japan Earthquake. Epilepsia, 54, e49-52.

Shibahara, S. (2009) The Upcoming $90^{\text {th }}$ anniversary of the Tohoku Journal of Experimental Medicine. Tohoku J. Exp. Med., 218, 161-163.

Shibahara, S. (2011) The 2011 Tohoku earthquake and devastating tsunami. Tohoku J. Exp. Med., 223, 305-307.

Shibahara, S. (2012) Revisiting the March 11, 2011 Earthquake and Tsunami: resilience and restoration. Tohoku J. Exp. Med., 226, $1-2$. 
Shibata, M., Hanzawa, K., Ueda, S. \& Yambe, T. (2013) Deep venous thrombosis among disaster shelter inhabitants following the March 2011 earthquake and tsunami in Japan: a descriptive study. Phlebology, [Epub ahead of print].

Shioiri, T., Nishimura, A., Nushida, H., Tatsuno, Y. \& Tang, S.W. (1999) The Kobe earthquake and reduced suicide rate in Japanese males. Arch. Gen. Psychiatry, 56, 282-283.

Stohl, A., Seibert, P., Wotawa, G., Arnold, D., Burkhart, J.F., Eckhardt, S., Tapia, C., Vargas, A. \& Yasunari, T.J. (2011) Xenon-133 and caesium-137 releases into the atmosphere from the Fukushima Dai-ichi nuclear power plant: determination of the source term, atmospheric dispersion, and deposition. Atmos. Chem. Phys. Discuss., 11, 28319-28394.

Suzuki, M., Uwano, C., Ohrui, T., Ebihara, T., Yamasaki, M., Asamura, T., Tomita, N., Kosaka, Y., Furukawa, K. \& Arai, H. (2011) Shelter-acquired pneumonia after a catastrophic earthquake in Japan. J. Am. Geriatr. Soc., 59, 1968-1970.

Takahashi, H., Fujimura, S., Ubukata, S., Sato, E., Shoji, M., Utagawa, M., Kikuchi, T. \& Watanabe, A. (2012) Pneumonia after earthquake, Japan, 2011. Emerg. Infect. Dis., 18, 19091911.

Tohma, K., Suzuki, A., Otani, K., Okamoto, M., Nukiwa, N., Kamigaki, T., Kawamura, K., Nakagawa, H. \& Oshitani, H. (2012) Monitoring of influenza viruses in the aftermath of the great East Japan earthquake. Jpn. J. Infect. Dis., 65, 542-544.

Tohoku University School of Medicine/Graduate School of Medicine. (2012) Records of the Great East-Japan Earthquake. Shibahara, S., Igarashi, K., Shindoh, C., Osumi, N., Funayama, M., Nagatomi, R., Dan, T., Nagami, F., Ohba, T., Rikiyama, T., Kagaya, Y., Yamanouchi, S. \& Yaegashi, N., editors. Tohoku University School of Medicine/Graduate School of Medicine (Masayuki Yamamoto), Sendai, Miyagi. 336p. (in Japanese). http://ir.library.tohoku.ac.jp/re/handle/ 10097/54278 or http://www.med.tohoku.ac.jp/d_report/index. html [Accessed: March 27, 2013].

Tokonami, S., Hosoda, M., Akiba, S., Sorimachi, A., Kashiwakura, I. \& Balonov, M. (2012) Thyroid doses for evacuees from the Fukushima nuclear accident. Sci. Rep., 2, 507.

Tokyo Electric Power Company. Fukushima Daiichi - A One Year
Review. http://www.tepco.co.jp/en/nu/fukushima-np/review/ index-e.html [Accessed: March 27, 2013].

Tsumune, D., Tsubono, T., Aoyama, M. \& Hirose, K. (2012) Distribution of oceanic ${ }^{137} \mathrm{Cs}$ from the Fukushima Dai-ichi Nuclear Power Plant simulated numerically by a regional ocean model. J. Environ. Radioact., 111, 100-108.

Ueda, S., Hanzawa, K., Shibata, M. \& Suzuki, S. (2012) High prevalence of deep vein thrombosis in tsunami-flooded shelters established after the Great East-Japan Earthquake. Tohoku J. Exp. Med., 227, 199-202.

World Health Organization. Preliminary dose estimation from the nuclear accident after the 2011 Great East Japan Earthquake and Tsunami. [Cited: May 23, 2012]. http://www.who.int/ ionizing_radiation/pub_meet/fukushima_dose_assessment/en/ index.html [Accessed: March 27, 2013].

Yamanda, S., Hanagama, M., Kobayashi, S., Satou, H., Tokuda, S., Niu, K. \& Yanai, M. (2013) The impact of the 2011 Great East Japan Earthquake on hospitalisation for respiratory disease in a rapidly aging society: a retrospective descriptive and cross-sectional study at the disaster base hospital in Ishinomaki. BMJ Open, 3, e000865.

Yamashita, F. (2008) Tsunami ten-den-ko: Kindai nihon no tsunami shi (History of Modern Japanese Tsunami). Shin Nihon Shuppansha, Tokyo. 235p. (in Japanese).

Yambe, T., Shibata, M., Sumiyoshi, T., Mibiki, Y., Osawa, N., Katahira, Y., Yambe, M., Tabayashi, K., Yamashina, M., Sato, E., Sato, S., Yagi, T., Watanabe, M., Akinno, Y., Munakata, M., Owada, N., Akiyama, M., Saiki, Y., Sugita, N. \& Yoshizawa, M. (2012) Medical responses following the Sendai quake (East Japan earthquake, March 11, 2011). Artif. Organs, 36, 760-763.

Yamori, K. (2013) Revisiting the concept of tsunami tendenko: tsunami evacuation behavior in the Great East Japan Earthquake. J. Disaster Res., 8, 115-116.

Yasunari, T.J., Stohl, A., Hayano, R.S., Burkhart, J.F., Eckhardt, S. \& Yasunari, T. (2011) Cesium-137 deposition and contamination of Japanese soils due to the Fukushima nuclear accident. Proc. Natl. Acad. Sci. USA, 108, 19530-19534. 